\title{
ANTIMICROBIAL EFFECT OF HERBAL VERSUS CHEMICAL MOUTHWASHES IN PATIENTS UNDERGOING ORTHODONTIC TREATMENT
}

\section{SAMEER AHMAD MALIK ${ }^{\mathrm{a} 1}$, CHANDRASHEKHAR HALLOLI ${ }^{\mathrm{b}}$, SUSHRUTH SHETTY ${ }^{\mathrm{c}}$ AND ROOPA TUBAKI ${ }^{\mathrm{d}}$}

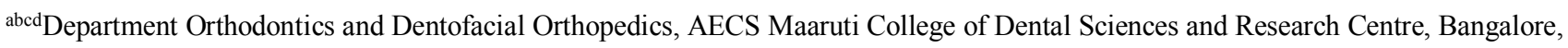
India

\begin{abstract}
The purpose of the study was to determine the efficacy of two different mouthwashes in patients undergoing fixed orthodontic treatment for prevention of white spot lesions. The study was conducted on 30 patients undergoing fixed orthodontic treatment between the ages of 15-25years. Patients were divided into 3groups - Group 1 control group, Group 2 using Clohex $0.2 \%$ for 30 sec twice daily and group 3 using Arimedadi Thailam mouth wash for 30sec twice daily. Samples from tooth surfaces were collected at $1^{\text {st }}$ day, $30^{\text {th }}$ day and $90^{\text {th }}$ day interval and were incubated for 48 hours. Colonies were counted using digital colony counter. : Clohex $0.2 \%$ and Arimedadi Thailam mouthwashes showed the maximum potential for the control of pathogenic organisms, and prevention of gingivitis and bacterial plaque inhibition than patients those were not using mouthwash.
\end{abstract}

KEYWORDS: Microbial Activity, Arimedadi Thailam, Digital Colony Counter Machine, Mouth Wash

Malocclusion is one of the most common ental disorders and is capable of increasing the risk of periodontal disease and dental caries. Optimum health of the periodontium should be maintained during the orthodontic treatment (Aghili et al., 2015). Maintaining oral hygiene is not a major problem while using removable appliances because they can be withdrawn from the oral cavity. However, fixed orthodontic appliances provide an additional surface for the collection of food debris and plaque resulting in increased bacterial colonization and subsequently, accentuate their luxuriant growth in supragingival and sub gingival region. The development of white spot lesions is almost inevitable when oral hygiene is poor. Demineralization is more commonly seen on the buccal surfaces of orthodontically treated teeth than on untreated teeth and it leads to increase in the incidence of caries (Isotupa et al., 1995). Several methods are required to reduce the microbial growth and plaque formation, mechanical or chemical method. In chemical method, antimicrobial mouth rinses are recommended as an adjunct to mechanical plaque control. Clohex $0.2 \%$ and Arimedadi Thailam mouthwash has been used in treating halitosis, plaque, and gingivitis (Kumar et al., 2006) (Dehghani et al., 2014) (Kumar et al., 2016). Hence, this study was designed to find out the most effective mouthwash in patients undergoing fixed orthodontic treatment so that white spot lesions can be prevented.

\section{MATERIALS AND METHODS}

The current study was conducted as a randomized controlled trial in the Department of Orthodontics and Dentofacial Orthopaedics, AECS Maaruti College of Dental Sciences and Research Center, Bangalore. The study sample included 30 patients in the age group between 15 to 25 years. Patients requiring fixed orthodontic treatment and devoid of any clinical evidence of pulpitis and impacted teeth were included. Exclusion criteria was presence of more than $5 \mathrm{~mm}$ crowding of teeth, presence of periodontal pathology, those taking any antibiotics, anti-inflammatory drugs and patients having systemic diseases. 30 patients were randomly divided into three groups and were kept under a specific oral hygiene regime.

\section{Arimedadi Thailam}

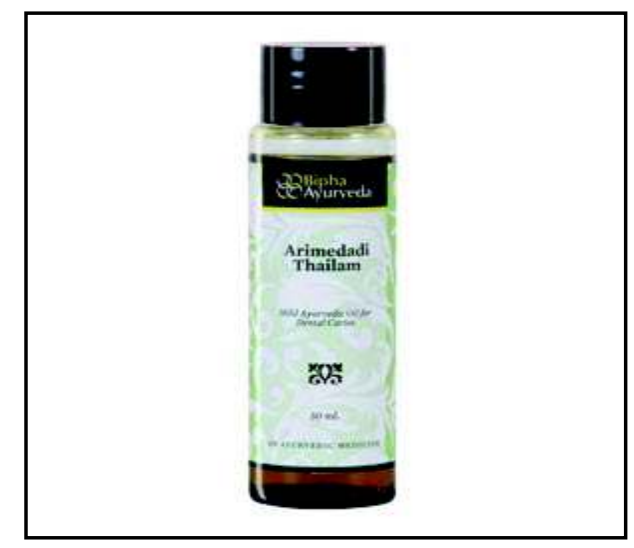


- Group 1 (Control group):- 10 patients undergoing regular orthodontic care (brushing the teeth with modified bass technique twice a day).

- Group 2:- 10 patients undergoing regular orthodontic care and prescribed with $10 \mathrm{ml}$ Clohex $0.2 \%$ mouthwash for 30 seconds twice daily.

- Group 3:- 10 patients undergoing regular orthodontic care and prescribed with $15 \mathrm{ml}$ Arimedadi Thailam mouthwash for 30 seconds twice daily.

Samples were taken on $1^{\text {st }}$ day, $30^{\text {th }}$ day and $90^{\text {th }}$ day interval. Microbiological trials were carried out on buccal surface of upper and lower first molars of all the patients at all intervals. Patients were examined and their dental plaque was scored by Silness and Loe "Plaque Index", and their gingival status was scored by Loe and Silness "Gingival Index". Patients were demonstrated with modified bass brushing technique, using super soft tooth brush and use of mouthwash. Oral prophylaxis was done in all the cases, to make tooth surface free from calculus, plaque and other deposits. Patients were instructed to follow their group regimes. After each interval, swab sample were collected and sent to the laboratory within 30 minutes where it was spread on small petridishes containing nutrient agar culture media for colonization.

Petridishes were incubated at $37^{\circ} \mathrm{C}$ in microaerophilic environment at 5\% CO2 for 48 hours. The colonies were counted using a digital colony counter machine and microbial counts were expressed as colony forming unit (CFUs/ml).

\section{Statistical Analysis}

Statistical analysis was performed Paired sample ttest was used to analyze the difference between all the study groups.

\section{RESULTS}

Comparative analysis of percentage reduction of microbial counts between the study groups is depicted in table 1 indicating the highest reduction in group 2 i.e. Clohex $0.2 \%$ group (55.44-66.01\%). The mean reduction in the bacterial count (table 2) was highest in group 2 (60.068 \pm 3.310$)$, and the lowest in group $1(8.695 \pm 1.278)$, while intermediate in the group $3(47.473 \pm 1.052)$ with all 3 values being highly significant $(\mathrm{p}=0.000)$. Table 2 shows the comparison between the three study groups for microbial count, where group 1 shows the maximum number of microbial count $(51.373 \pm 3.967)$.

Table 1: Mean percentage reduction of microbial count

\begin{tabular}{|c|c|c|c|c|}
\hline \multicolumn{2}{|c|}{ Parameters } & Group 1 & Group 2 & Group 3 \\
\hline \multicolumn{2}{|c|}{ Mean \pm SD } & $8.79 \pm 1.27$ & $60.17 \pm 3.31$ & $47.44 \pm 1.05$ \\
\hline \multicolumn{2}{|c|}{$\begin{array}{c}\text { Std. Error } \\
\text { Mean }\end{array}$} & 0.454 & 1.047 & 0.333 \\
\hline \multicolumn{2}{|c|}{ t-test } & 21.31 & 57.36 & 142.66 \\
\hline \multicolumn{2}{|c|}{ Df } & 9 & 9 & 9 \\
\hline \multicolumn{2}{|c|}{ p-value } & $0.000^{*}$ & $0.000^{*}$ & $0.000^{*}$ \\
\hline \multirow{2}{*}{$\begin{array}{c}95 \% \\
\text { CI }\end{array}$} & Upper & 9.61 & 62.43 & 48.23 \\
\hline & Lower & 7.78 & 57.700 & 46.620 \\
\hline
\end{tabular}

Table 2: Intergroup Comparison of Percentage Reduction of Microbial Count for All the Study Groups

\begin{tabular}{|c|c|c|c|c|c|c|c|}
\hline $\begin{array}{c}\text { Intergroup } \\
\text { comparison }\end{array}$ & Mean $\pm \mathrm{SD}$ & $\begin{array}{c}\text { Standard Error } \\
\text { of Mean }\end{array}$ & \multirow{2}{*}{ t-test } & \multirow{2}{*}{$\mathrm{N}$} & $\mathrm{p}$-value & \multicolumn{2}{|c|}{$95 \% \mathrm{CI}$} \\
\cline { 5 - 8 } & & & & & Lower & Upper \\
\hline Group 1 vs. 2 & $-51.47 \pm 4.02$ & 1.254 & -40.95 & 9 & $0.000^{*}$ & -54.21065 & -48.53535 \\
\hline Group 1 vs. 3 & $-38.68 \pm 1.41$ & 0.449 & -86.42 & 9 & $0.000^{*}$ & -39.79304 & -37.76296 \\
\hline Group 2 vs. 3 & $12.58 \pm 4.05$ & 1.053 & 11.96 & 9 & $0.000^{*}$ & 10.21207 & 14.97793 \\
\hline
\end{tabular}

Table 3 analyses the significance relation between the study groups to evaluate the change in plaque index after 3 months. It was found that group $1(1.55 \pm 1.10)$ showed a non-significant relation; whereas group 2 $(12.05 \pm 8.52)$ and group $3(10.29 \pm 7.28)$ showed a significant relation. The intergroup comparison between plaque index showed the least difference in reduction of Plaque Index between Group 2 and Group 3 (9.19 \pm 0.98$)$, and the maximum difference between Group 1 and Group $2(49.17 \pm 0.66)$ followed by Group 1 and Group 3 (39.98 \pm 0.56$)$. 
MALIK ET. AL.: ANTIMICROBIAL EFFECT OF HERBAL VERSUS CHEMICAL MOUTHWASHES IN...

Table 3: Change in the Plaque Index after 3 Months

\begin{tabular}{|c|c|c|cr|}
\hline Groups & Mean $\pm \mathrm{SD}(\mathrm{n}=10)$ & t-test & \multicolumn{2}{|c|}{$\mathrm{p}$-value } \\
\hline Group 1 & $1.46 \pm 1.10$ & 21.260 & $0.073 * *$ & $\mathrm{NS}$ \\
\hline Group 2 & $12.15 \pm 8.51$ & 52.619 & $0.022 *$ & $\mathrm{~S}$ \\
\hline Group 3 & $10.39 \pm 7.32$ & 38.255 & $0.039 *$ & $\mathrm{~S}$ \\
\hline
\end{tabular}

Table 4 shows one sample t-test to analyze the change in gingival index after 3 months. We found that group 1 (1.36 \pm 0.96$)$ showed a non-significant relation; whereas groups $2(10.28 \pm 7.27)$ and $3(7.73 \pm 5.46)$ showed a significant relation. The intergroup comparison of plaque index is shown in table 5 and was found to be highly significant. The least difference in reduction of gingival index was seen between group 2 and $3(7.93 \pm 2.48)$, and the maximum difference was seen between group 1 and 2 (49.09 \pm 2.63$)$ followed by group 1 and 3 (41.16 $\pm 0.1 .69)$.

\section{DISCUSSION}

The idea of employing a chemical agent which would act in an identical manner to a toothbrush and remove bacteria from the tooth surface is an attractive proposition. This chemical agent contained in mouth rinse would be expected to reach all tooth surfaces and thereby be totally effective. Chemical plaque removal agents have attracted the terminology of "the chemical toothbrush" (Mandel, 1988). In this study, two different mouthwashes were used - Clohex $0.2 \%$ mouthwash and Arimedadi Thailam mouthwash.

Table 4: Change in Gingival Index after 3 Months

\begin{tabular}{|c|c|c|c|}
\hline Groups & Mean $\pm \mathrm{SD}(\mathrm{n}=10)$ & $\mathrm{t}$-test & $\mathrm{p}$-value \\
\hline Group 1 & $1.35 \pm 1.01$ & 14.176 & $0.076^{* *} \mathrm{NS}$ \\
\hline Group 2 & $10.27 \pm 7.27$ & 42.546 & $0.028^{*} \mathrm{~S}$ \\
\hline Group 3 & $7.72 \pm 5.46$ & 35.127 & $0.037^{*} \mathrm{~S}$ \\
\hline
\end{tabular}

The Clohex $0.2 \%$ mouthwash contains a stabilized chlorine dioxide. Chlorine dioxide $\left(\mathrm{ClO}_{2}\right)$ is an oxidizing agent with known bactericidal, virucidal and fungicidal properties. It inhibits microorganism growth by disruption of the transport of nutrients across the cell membrane. $\mathrm{ClO}_{2}$ oxidatively consumes and inactivates salivary biomolecules, including pyruvate, methionine, trimethylarnine, tyrosine and glycine; thereby, exerting its antimicrobial effect.

Table 5: Intergroup Comparison of Plaque Index

\begin{tabular}{|c|c|c|c|c|c|c|c|}
\hline Intergroup comparison & Mean \pm SD & $\begin{array}{c}\text { Standard Error } \\
\text { of Mean }\end{array}$ & t-test & \multirow{2}{*}{$\mathrm{N}$} & \multirow{2}{*}{ p-value } & \multicolumn{2}{|c|}{$95 \% \mathrm{CI}$} \\
\cline { 5 - 8 } & $49.09 \pm 2.63$ & 0.83242 & -58.956 & 9 & $0.000^{*}$ & -50.97152 & -47.20448 \\
\hline Group 1 vs 2 & $41.16 \pm 2.01$ & 0.53372 & -77.095 & 9 & $0.000 *$ & -42.36259 & -39.94741 \\
\hline Group 1 vs 3 & $7.93 \pm 3.02$ & 0.78520 & 10.095 & 9 & $0.000 *$ & 6.15540 & 9.71060 \\
\hline
\end{tabular}

A reduction product of chlorine dioxide, chlorite also acts as a reactive oxidant towards biomolecules like endogenous thiols such as cysteine. $\mathrm{ClO}_{2}$ being highly soluble in water can penetrate into the biofilm rapidly and exert its antimicrobial action. Stabilized $\mathrm{ClO}_{2}$ refers to the generation and subsequent sequestration of chlorite, which allows for its storage and increases its shelf-life (Mandel, 1988) (Yadav et al., 2015).

Arimedadi Thailam mouthwash has antimicrobial, antiplaque, antiseptic, analgesic and refreshing properties. It is an herbal preparation, made from a combination of natural herbs with beneficial properties of:

1. Manjishtha (Rubia cordifolia)
2. Khadira (Acacia catechu),

3. Til oil (Sesamum inidicum),

4. Clove (Syzygium aromaticum)

5. Many other ingredients

Fard et al.,, 2011 evaluated the effect of Orthokin, Listerine and Oral B mouthwash on the Mutans Streptococcus (MS) and plaque index in orthodontic patients. These factors were measured before and after 21 days of mouthwash use. They concluded that Ortho-kin was more effective than the other mouthwash in reducing MS and plaque index around the orthodontic brackets. In the present study, modified bass brushing technique was 
MALIK ET. AL.: ANTIMICROBIAL EFFECT OF HERBAL VERSUS CHEMICAL MOUTHWASHES IN...

advised for the cleaning of all the surfaces of tooth. It is standard brushing technique and widely accepted by the dental professionals. Therefore; recommended modified bass techniques were used by all participants and were advised to use same type of tooth brush and toothpaste (Kumar et al., 2066). The data thus collected were subjected to statistical analysis by classifying into three categories: 1) Total colony forming units (CFU); 2) plaque accumulation; and 3) gingival condition.

\section{Total Colony Forming Unit}

A comparison of the total CFU of various mouth washes revealed that Clohex $0.2 \%$ mouthwash was the most effective in reducing total CFU followed by Arimedadi Thailam mouthwash than the control group.

\section{Plaque Accumulation}

Clohex $0.2 \%$ mouthwash was most efficient in reducing plaque from the tooth surface, on which edgewise appliance is fixed (12.05 \pm 8.52$)$, followed by Arimedadi Thailam mouthwash $(10.29 \pm 7.28)$, and least efficient was the routine care $(1.56 \pm 1.10)$. This was in accordance with the study conducted by Sarangal et al., 2014 who also found significant reduction in plaque and gingival indices after use of both Arimedadi Thailam and Chlorhexidine mouthwash. Kaur et al., 2014 also demonstrated highly significant reduction in gingival index and OHI-S after use of Arimedadi Thailam mouthwash. Abhishek et al., 2013 and Kumar et al., 2016 also showed a significant reduction in Plaque and Gingival Index after use of $\mathrm{ClO}_{2}$ mouthwash which was in accordance with our study (Sarangal et al., 2014) (Kandwal and Ghani, 2014). However, none of these studies were carried out in orthodontic patients.

\section{Gingival Condition}

Clohex $0.2 \%$ mouthwash was very effective in reducing gingivitis $(10.28 \pm 7.27)$ followed by Arimedadi Thailam mouthwash $(7.73 \pm 5.46)$. The routine care was the least effective (1.36 \pm 0.96$)$ method in reducing gingivitis. A similar comparative assessment of plaque index in different groups again reveals highly significant differences between different groups (control vs. Clohex $0.2 \%$; control vs. Arimedadi Thailam and Clohex $0.2 \%$ vs Arimedadi Thailam mouthwash). The results thus obtained may be due to variation in composition of mouth washes. The reduction in total $\mathrm{CFU}$, plaque accumulation, gingivitis from the base line may be attributed to proper brushing method and conscious oral rinsing. The study showed that the use of mouthwashes in conjunction with oral hygiene procedures during longer orthodontic treatment plays an important role in maintaining the oral hygiene of the patients. Patients derive both functional and aesthetic benefits from orthodontic treatment. Based on the findings of this study, it is evident that patients wearing orthodontic appliances have a problem in maintaining good oral hygiene. Inadequate oral home care among orthodontic patients may make them more prone to develop gingivitis during orthodontic treatment. Therefore, educating and motivating these patients, to maintain their oral health and providing recommendations for oral home care aid to improve their compliance, remains the cornerstone for achieving optimal oral hygiene results. It is, therefore, essential that oral hygiene instructions and a hygiene maintenance program not be overlooked during orthodontic treatment.

\section{CONCLUSION}

Clohex $0.2 \%$ mouthwash showed the maximum potential for the control of pathogenic organisms, and prevention of gingivitis and bacterial plaque inhibition. Arimedadi Thailam used as mouthwash is found to be effective in reduction of total colony forming units, gingivitis and plaque accumulation but is less effective than Clohex $0.2 \%$. Patients who were not using mouthwash were found to be least effective.

\section{REFERENCES}

Aghili H., Jafari A., Nadoushan and Herandi V., 2015. Antimicrobial Effect of Zataria Multiflora Extract in Comparison with Chlorhexidine Mouthwash on Experimentally Contaminated Orthodontic Elastomeric Ligatures. J. Dent. (Tehran), 12(1): 110.

Bagchi S., Saha S., Jagannath G.V., Reddy V.K. and Sinha P., 2015. Evaluation of efficacy of a commercially available herbal mouthwash on dental plaque and gingivitis: A double-blinded parallel randomized controlled trial. J. Indian Assoc. Public Health Dent., 13: 222-7.

Dehghani M., Abtahi M., Sadeghian H., Shafaee H. and Tanbakuchi B., 2014. Combined chlorhexidinesodiumfluoride mouthrinse for orthodontic 
patients: Clinical and microbiological study. J. Clin. Exp. Dent., 7(5): e569-e575.

Fard B.K., Ghasemi M., Rastgariyan H., Sajjadi S.H., Emami H. and Amani M., 2011. Effectiveness of Mouth Washes on Streptococci in Plaque around Orthodontic Appliances. ISRN Dent., 954053.

Isotupa K.P., Gunn S., Chen C.Y., Lopatin D. and Makinen K.K., 1995. Effect of polyol gums on dental plaque in orthodontic patients. Am. J. Orthod Dentofac Orthop., 107: 497- 504.

Kumar R., Kapoor D., Jain A. and Tandon P., 2006. Microbicidal Effect of Different Mouthwashes on Patients Undergoing Fixed Orthodontic Treatmnent. J. Ind. Orthod. Soc., 39:139-146.

Kumar S.Y., Acharya S., Urala A. and Pentapatid K., 2016. Effect of Aloe vera, chlorine dioxide, and chlorhexidine mouth rinses on plaque and gingivitis: A randomized controlled trial. J. Oral Biol. Craniofac Res., 6(1): 54-8.

Kandwal A. and Ghani B., 2014. A comprative evaluation of effect ofchlorine dioxide mouthrinse on plaque induced gingivitis and oral malodor: a clinical study. Int. J. Dent. Health Sci., 1: 24-33.

Mandel I.D., 1988. Chemotherapeutic agents for controlling plaque and gingivitis. J. Clin. Periodontal, 15: 488498.

Sarangal V., Kaur S., Singh S., Suman S., Kaur N. and Malhotra S., 2014. Evaluation of clinical efficacy and safety of commercially available herbal mouthwash in comparison with chlorhexidine mouthwash (aster-x) in improving oral health in patients undergoing dental procedures. BFUDJ, 5(2): 38-42.

Shetty S., Pillai S. and Rahul A., 2013. Asian Journal of Pharmaceutical Technology \& Innovation, 1(3):11.

Yadav S., Kini V. and Padhye A., 2015. Inhibition of Tongue Coat and Dental Plaque Formation by Stabilized Chlorine Dioxide Vs Chlorhexidine Mouthrinse: A Randomized, Triple Blinded Study. J. Clin. Diagn. Res., 9(9): ZC69-ZC74. 